\title{
Study on Population Fluctuation of Thrips tabaci (L.) on Cluster Cultivars in Ultra Narrow System in the Field's Cotton Golestan Province of Iran
}

\author{
Mojeni Taghi Darvish \\ Cotton Research Institute of Iran, Agricultural Research, Education and Extension Organization (AREEO), Gorgan, Iran \\ Email address: \\ t_mojeni@yahoo.com

\section{To cite this article:} \\ Mojeni Taghi Darvish. Study on Population Fluctuation of Thrips tabaci (L.) on Cluster Cultivars in Ultra Narrow System in the Field's \\ Cotton Golestan Province of Iran. Animal and Veterinary Sciences. Vol. 9, No. 3, 2021, pp. 46-49. doi: 10.11648/j.avs.20210903.11
}

Received: April 14, 2021; Accepted: May 11, 2021; Published: May 31, 2021

\begin{abstract}
In the planting system, very narrow row spacing with spacing of rows between 20 and $40 \mathrm{~cm}$ is considered. This planting method increases production. Experiments to study and compare the population thrips on 3 cluster variety and one check cultivar, using the method of narrow planting distance of $20 \times 20$ and $20 \times 80 \mathrm{~cm}$ in the form of factorial design in the form of a randomized complete block design with 3 replications in Hashemabad cotton research station in Gorgan during the two years 20182019 was evaluated. Statistics of different stages of the thrips pest it was recorded weekly in the tested treatments and recorded in special tables. Based on studies the results of combined analysis of variance show that the yield in the cultivars tested in Sajedi ${ }^{\circledR}$ cultivar with a distance of $80 \mathrm{~cm}$ with an average yield of $1696 \mathrm{gr}$ in the plot and Golestan ${ }^{\circledR}$ cultivar $80 \mathrm{~cm}$ with $1622.9 \mathrm{gr}$ in the plot with the highest yield and T2 $\AA$ cultivar with a distance of $20 \mathrm{~cm}, 847.2 \mathrm{gr}$ in plot had the lowest yield. Infestation rate of cluster cultivars tested in very narrow cultivation thrips population density in Golestan ${ }^{\circledR}$ cultivars with a distance of $80 \mathrm{~cm}$ and Sajedi ${ }^{\circledR}$ with a distance of $20 \mathrm{~cm}, 1.723$ thrips per leaf with the most infestation and Golestan ${ }^{\circledR}$ cultivar with a distance of $20 \mathrm{~cm}, 1.388$ thrips least infestation was measured in leaves. Therefore Golestan ${ }^{\circledR}$ cultivar with an average yield and thrips population infestation, the lowest cotton cultivation in agriculture ultra-narrow row 20 centimeters had in the cotton fields.
\end{abstract}

Keywords: Thrips tabaci, UNR, Cotton, Golestan Province

\section{Introduction}

Compared to the more spaced row spacing system, there will be evident changes in the number of bolls per plant and the state of the canopy. In this system, the number of bolls per plant is reduced and the height of the plant and the length of branches are decreased. (Galanopoulous, et al., 1980) [5]. Reducing cotton production costs, especially through early maturity, reducing pesticide use by interrupting the critical cycle of pests, reducing irrigation water consumption is one of the benefits of dense planting and in different ways, including planting narrow and very narrow intervals, plating a clump. Also, with the advent of mechanized, early harvesting of cotton has become very important. Agronomic and environmental factors that have a great effect on the precociousness of the product, we can plant density, Plant pest control, nitrogen fertilizer management and proper irrigation periods. More densities generally increase aging, but management of such farms is very important. In this type of farming, due to increased competition, the loss of buds increases, which in each plant leads to a decrease in yields (Kucheki, 1985) [8].

In the planting system, the row spacing is very narrow, where the planting row spacing is considered to be between 20 and 40 $\mathrm{cm}$. The advantages of this planting method include increasing early maturity as well as crop yield under drier climatic conditions (Philip, 2000 and 2001) [12, 13]. In the planting system, very narrow row spacing with spacing of rows between 20 and $40 \mathrm{~cm}$ is considered (Kirby, et al., 1990) [7]. Increasing prematurity leads to reducing pesticide consumption and is one of the important factors in reducing production costs and reducing environmental pollution. Prematurity is increased by reducing the number of bolls per plant (Bin Mohamad and Sappenfield, 1982) [1]. Simultaneous ripening of bolls or their faster maturation leads to more efficient use of hormones, insecticides, and increased yield (Jesus Rossi, et al., 2004) [9]. In one study (Wright, et al., 2011) [14] the main goal was to 
determine cultivars that did not suffer from yield loss and quality traits at very high densities. Early, medium clay and full clay were applied. The fiber yield of an early cultivar and limited growth was not affected by density but in the case of full clay cultivar and unlimited growth, yield decreased with increasing density. In another study (Philip, 2001) [13], three densities were performed by spacing 25,50 , and $100 \mathrm{~cm}$ with three cotton varieties. It was concluded that density was highly effective on morphological traits and yield components and higher densities reduced vegetative growth and crop production of each plant, although more dry weight was obtained per unit area in the latter condition. Medium densities showed higher maturity and higher yield compared to higher densities, no significant differences were observed between cultivars. Also, the interaction effect of cultivars on density was not significant. In studies conducted on the rate of infection of successful cotton lines to major pest killers of the Tbl-180, N2G80, Skt-133 and Skt-134 lines in comparison with the common cultivar of Golestan province, the most common pests have the lowest amount of infection. In researches on the amount of infection of the population of sucking pests in Golestan province, the Skt-134, Tbl-80 and N2G80 hybrids has the least infection with the major suckling pests such as thrips, aphids, whitefly and cotton leafhoppers (Darvish Mojeni, 2012, 2013) [2, 3]. In all cultivars, the highest yield was obtained at high plant densities, so that the highest yield in Sahel cultivar was observed at plant densities of 125,000 plants per hectare, In the cultivar Saiokra 324 at a plant density of 125000 and 62500 plants and In Zeta-2 cultivar, 125000 plants were also reported. There are different opinions about the effect of row spacing on performance in different studies. Cotton farming is expanding in Ultra-Narrow Row in cotton growing countries (Ghajari and Ghadrei, 2006) [6]. In a very narrow row spacing system where the row spacing is considered to be between 20 and $40 \mathrm{~cm}$, there will be obvious changes in terms of the number of bolls per plant (Donyavian, 1999) [4]. Thrips population density is very narrow gap in agriculture, the yield rate of the tested intervals Golestan ${ }^{\circledR}$ cultivar distance of $80 \mathrm{~cm}$ with an average yield of $4422.87 \mathrm{gr} /$ plots maximum yield and Sepid ${ }^{\circledR}$ with a distance of $25 \mathrm{~cm}$ with an average yield of $3108.33 \mathrm{gr} / \mathrm{plots}$ had the lowest yield. Infestation of the tested varieties in cultivation are very narrow thrips populations on Sahel ${ }^{\circledR}$ and Golestan ${ }^{\circledR}$ cultivar with $25 \mathrm{~cm}$ respectively, 3.52 and 3.11 thrips per leaf has the highest infestation and number density on Sahel ${ }^{\circledR}$ with distance $80 \mathrm{~cm}, 1.24$ thrips per leaf have shown minimal infection. Therefore Golestan ${ }^{\circledR}$ cultivar with an average yield important sucking pests such as thrips population infestation, the lowest cotton cultivation in agriculture ultranarrow row 80 and 25 centimeters had in the cotton fields (Mojeni, 2019) [10]. Infestation rate of cluster cultivars tested in very narrow cultivation of green aphid population density on Sajedi cultivars with a distance of $80 \mathrm{~cm}$ and the khorshid with a distance of $20 \mathrm{~cm}$ with densities of 41.39 and 40.36 aphids per leaf, respectively, with the highest aphids per leaf and cultivars $\mathrm{T} 2$ and the khorshid with a distance of $20 \mathrm{~cm}$ with 23.59 and 29.04 aphids, respectively. They had the least infestation in the leaves (Mojeni, 2021) [11].

\section{Material and Methods}

This research was conducted in Hashemabad cotton research station in Gorgan. The treatments included 3 cotton cluster cultivars (Khorshid ${ }^{\circledR}, T 2 \AA$ and Sajedi ${ }^{\circledR}$ ) and check (Golestan ${ }^{\circledR}$ cultivar) and with two narrow planting intervals of $20 \times 20$ and $20 \times 80 \mathrm{~cm}$ were evaluated factorially in a randomized complete block design with three replications. Each plot consisted of 10 planting lines of $12 \mathrm{~m}$ with planting pattern. Two side lines and half meters from the beginning and end of each row are considered as margins and all statistics were performed from the middle rows. To study population changes of thrips regular weekly and random sampling was done on plants in each plot of 15 leaves for thrips pest the number of nymphs and adults were counted on them and recorded in special tables. The performance of each experimental plot after the removal of two lateral lines and one meter margin from the beginning and the end of each row were measured all records were taken from the middle rows. The obtained data were analyzed as a factorial experiment in a randomized complete block design using SAS software and the mean data were compared by LSD test.

\section{Results and Discussion}

Based on studies conducted during two years of experimentation and statistical analysis, data conversion and combined analysis of variance shows: In terms of average yield, the amount of yield obtained in the cluster cultivars tested in very narrow agriculture by performing combined analysis of variance in Sajedi ${ }^{\circledR}$ cultivar with a cultivation distance of $80 \mathrm{~cm}$ with $1696 \mathrm{gr}$ and Golestan ${ }^{\circledR} 80 \mathrm{~cm}$ with $1622.9 \mathrm{gr}$ in plot has the highest yield in plot in group a and cultivars Golestan ${ }^{\circledR}$ and T2 ${ }^{\circledR}$ with a distance of $20 \mathrm{~cm}$ with 867.4 and $847.2 \mathrm{gr} /$ in plot in group $\mathrm{c}$ with the lowest yield at the level of $5 \%$ showed a significant difference (Tables 1 and 2).

Table 1. Analysis of composite variance related to cotton yield (gr/plot) in cluster cultivars in very narrow agriculture at Hashemabad station 20182019 .

\begin{tabular}{lllll}
\hline Sources of changes & df & S.S & MS & F \\
\hline Rep. & 2 & 0.226 & 0.113 & $0.71 \mathrm{~ns}$ \\
Treat. & 7 & 0.307 & 0.044 & $0.28^{* *}$ \\
year & 1 & 7.821 & 7.821 & $49.10^{* *}$ \\
Erro. & 37 & 5.894 & 0.159 & \\
CV & $14.17 \%$ & & & \\
\hline
\end{tabular}

Table 2. Comparison of mean LSD and grouping of performance-related treatments.

\begin{tabular}{|c|c|c|}
\hline Treat. (variety) & Average yield (gr/plot) & $5 \%$ \\
\hline Sajedi® $80 \mathrm{~cm}$ & 1696 & $\mathrm{a}$ \\
\hline Golestan $® 80 \mathrm{~cm}$ & 1622.9 & $\mathrm{a}$ \\
\hline Khorshid $® 80 \mathrm{~cm}$ & 1295 & $a b$ \\
\hline $\mathrm{T} 2 ® 80 \mathrm{~cm}$ & 1196.1 & $a b$ \\
\hline Sajedi® $20 \mathrm{~cm}$ & 1039.7 & $\mathrm{~b}$ \\
\hline Khorshid $® 20 \mathrm{~cm}$ & 913.3 & $\mathrm{~b}$ \\
\hline Golestan $® 20 \mathrm{~cm}$ & 867.4 & bc \\
\hline $\mathrm{T} 2 \AA 20 \mathrm{~cm}$ & 847.2 & c \\
\hline
\end{tabular}

In terms of infestation rate to cotton thrips population in 
cluster cultivars tested in very narrow crops by combined analysis of variance of Golestan ${ }^{\circledR}$ and Sajedi ${ }^{\circledR}$ cultivars with a distance of 80 and $20 \mathrm{~cm}$ with a density of 1.723 per leaf, respectively, has the highest infection in group a and Golestan ${ }^{\circledR}$ cultivars. T2 ${ }^{\circledR}$ cultivar with a distance of $20 \mathrm{~cm}$ with a density of 1.388 and 1.498 numbers per leaf in group $b$ and $\mathrm{c}$ at the level of $5 \%$ compared to the control showed a significant difference (Tables 3, 4 and Figure 1).

Table 3. Analysis of composite variance related to the effect of very narrow agriculture on the population of Thrips tabaci (L.) On cluster cultivars in Hashemabad station 2018-2019.

\begin{tabular}{lllll}
\hline Sources of changes & df & S.S & MS & F \\
\hline Rep. & 2 & 0.074 & 0.037 & $0.52 \mathrm{~ns}$ \\
Treat. & 7 & 0.595 & 0.085 & $1.20^{* *}$ \\
year & 1 & 0.148 & 0.148 & $2.09^{*}$ \\
Erro. & 37 & 2.628 & 0.071 & \\
CV & $17 / 13 \%$ & & & \\
\hline
\end{tabular}

Table 4. Comparison of mean LSD and grouping related to a population density of cotton thrips in treatments.

\begin{tabular}{|c|c|c|}
\hline Treat. (varity) & Thrips (Num/leaf) average. & $5 \%$ \\
\hline Golestan $® 80 \mathrm{~cm}$ & $1.723 \pm 0.012$ & $\mathrm{a}$ \\
\hline Sajedi ${ }^{\circledR} 20 \mathrm{~cm}$ & $1.721 \pm 0.009$ & $\mathrm{a}$ \\
\hline Khorshid $® 80 \mathrm{~cm}$ & $1.611 \pm 0.019$ & $a b$ \\
\hline Khorshid $(20 \mathrm{~cm}$ & $1.502 \pm 0.018$ & $\mathrm{ab}$ \\
\hline Sajedi ${ }^{\circledR} 80 \mathrm{~cm}$ & $1.500 \pm 0.002$ & $a b$ \\
\hline $\mathrm{T} 2 \AA 80 \mathrm{~cm}$ & $1.500 \pm 0.002$ & $a b$ \\
\hline $\mathrm{T} 2 \AA 20 \mathrm{~cm}$ & $1.498 \pm 0.003$ & $\mathrm{bc}$ \\
\hline Golestan $® 20 \mathrm{~cm}$ & $1.388 \pm 0.110$ & $\mathrm{c}$ \\
\hline
\end{tabular}

Thrips pest is active in cotton fields of Gorgan region from May to late June from the 2-leaf stage to the 6-8-leaf stage of the cotton plant and causes damage to cotton fields (Darvish Mojeni 2012) [2]. According to the results of this study, in very narrow agriculture, the population of thrips has decreased. Golestan ${ }^{\circledR}$ cultivar with a distance of $25 \mathrm{~cm}, 3.52$ thrips per leaf has the highest density and the same cultivar with a distance of $80 \mathrm{~cm}, 3.11$ thrips per leaf is placed in the next group. Sepid $®$ cultivar with a distance of $80 \mathrm{~cm}$ had 1.24 thrips per leaf. In the 2013 study, the population of Thrips was less dense than in 2013 due to cold and humid weather conditions at the beginning of the season. Sahel cultivar with a distance of 25 per year $2013 \mathrm{~cm}$ with 3.11 thrips per leaf had the highest density and Sepid ${ }^{\circledR}$ cultivar with a distance of $25 \mathrm{~cm}$ with 2.14 thrips per leaf had the lowest infestation. Therefore, plant density higher per unit area, the thrips very is population on the cotton plant. This is due to the better shading level for thrips activity (Darvish, Mojeni, 2013) [3].

In the studied cluster cultivars, Golestan $\AA$ and Sajedi $\AA$ cultivars with densities of 1.723 and 1.721 had the highest infestation per leaf and $T 2 \AA$ and Golestan $\AA$ cultivars with a distance of $20 \mathrm{~cm}$ with densities of 1.498 and 1.388 per leaf cultivars had the lowest density. This has been done with research that cultivating a very narrow row of cotton production can have a significant impact on insect management (Mojeni, 2019) [10]. Pests such as aphids, whiteflies and thrips can be indirectly controlled with a very narrow culture system (Jesus Rossi, et al., 2004) [9], which is consistent with the studies in this study. Study: Increasing the number of cotton plants from 50,000 plants per hectare to 125,000 plants per hectare the population of important sucking pests such as thrips, aphids and whitefly were easily controlled due to the increase of their natural enemies in the cotton field (Wright, et al., 2015) [15].

\section{Conclusion}

Based on the results of analysis of variance and comparison of mean yield of cultivars, Golestan ${ }^{\circledR}$ and $T 2 \AA$ cultivars have good yield in very narrow cultivation with an average of $867.4-847.2 \mathrm{gr}$ per plot and the lowest population density of thrips $1.388-1.498$ num/leaf and are recommended to farmers for this cultivation method.

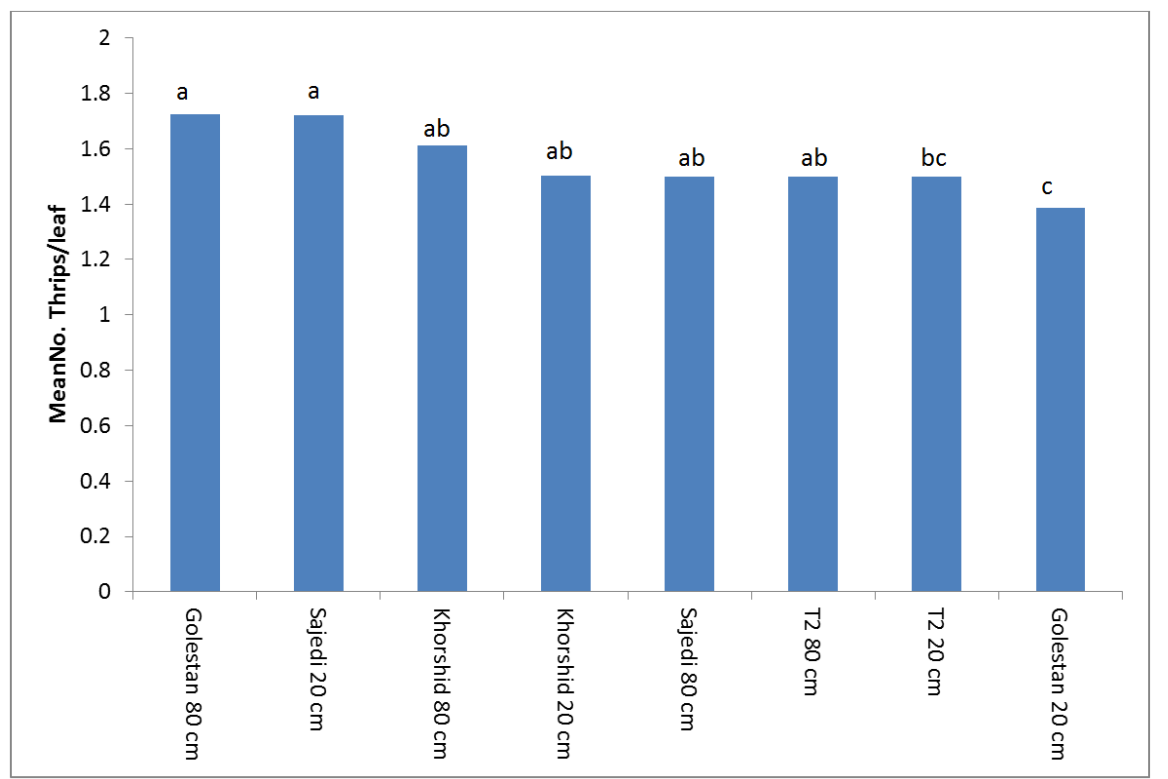

Figure 1. Mean changes of population Thrips tabaci (L.) on cotton cluster cultivars in Golestan province 2018-2019. 


\section{References}

[1] Bin Mohamad K, Sappenfield W P. 1982. Cotton cultivar response to plant populations in a short-season, narrow row cultural system. Agron. j. 74: 619-625.

[2] Darvish Mojeni, T. 2012. The final report on the infestation of complementary access important sucking pests of cotton successful lines in Golestan rovince. Num. 40745. Cotton Research Institute of Iran. 41p.

[3] Darvish Mojeni, T. 2013. The final report evaluation of hybrid infestation privileged to important sucking pest population. Num. 44607. Cotton Research Institute of Iran. 30p.

[4] Donyavian, H. 1999. Investigation of the effect of density on yield and quality characteristics of Sahel Varity cotton in heap planting. Cotton Research Institute of Iran. 86p.

[5] Galanopoulous, S.; Shicas, S. and Gerakis, A. 1980. Effect of population density, plant date, and genotype of plant growth and development of cotton. Agron. J. 72: 347-352.

[6] Ghajari, A. and Ghadrei, F. 2006. Row spacing effect on plant density on yield and components of cotton in the Gorgan. Journal of Agriculture. P: 833-844.

[7] Kerby, T. A.; Cassman, K. G. and Keeley, M. 1990. Genotypes and plant densities for narrow row cotton cystems. I. Heigth. nodes. earliness and location of yield. Crop Sci. 36: 644-649.

[8] Kucheki, A. 1985. Agriculture in the dry areas. Pub. Univ. Of Mashad. 202p.

[9] Jesus Rossi, G.; Novick, J.; Murray, J.; Landivar, S.; Zhang, D.; Baxevanos, A.; Mateos, T.; Kerby,; Hake, K. and Krieg, D. 2004. Ultra Narrow Row Cotton: Global Perspective. 63rd Plenary Meeting of the International Cotton Advisory Committee, Mumbai, India November 2004.

[10] Mojeni, T. D. 2019. Study on Ultra Narrow Row system in cotton culture on population dynamic of Thrips tabaci (L.) in the fields' of Golestan. province. Jou. Nov. Appli. Sci. Vol. 8 (8) p: 166-169.

[11] Mojeni, T. D. 2021. Survey on population changes of Aphis gossypii (Glove) on cluster cultivars in Ultra Narrow Row system in the field cotton Golestan Province. Egypt. Acad. J. Biology. Sci., 14 (1): 93-97.

[12] Philip, H. Jost. 2000. Growth and yield comparisons of cotton planted in conventional and ultra-narrow row spacing. Crop sci. 40: 430-435.

[13] Philip, H. Jost. 2001. Phenotypic alternations and crop maturity differences in ultra-narrow and conventional spaced cotton. Crop Sci: 41: 1150-1159.

[14] Wright, D. L.; Marois, J. J.; Sprenkel, R. K. and Rich, J. R. 2011. Production of Ultra Narrow Row Cotton. Institute of Food and Agricultural Sciences, University of Florida. Website at http://edis.ifas.ufl.edu.

[15] Wright, D. L.; Marois, J. J. and Sprenkel, R. K. 2015. Production of Ultra Narrow Row Cotton. Institute of Food and Agricultural Sciences, University of Florida. publication, SSAGR-83. 